\title{
Oxygen and cancer
}

Citation for published version (APA):

Lambin, P. (2001). Oxygen and cancer: friends or enemies? Maastricht University. https://doi.org/10.26481/spe.20010914pl

Document status and date:

Published: 14/09/2001

DOI:

10.26481/spe.20010914pl

Document Version:

Publisher's PDF, also known as Version of record

\section{Please check the document version of this publication:}

- A submitted manuscript is the version of the article upon submission and before peer-review. There can be important differences between the submitted version and the official published version of record.

People interested in the research are advised to contact the author for the final version of the publication, or visit the DOI to the publisher's website.

- The final author version and the galley proof are versions of the publication after peer review.

- The final published version features the final layout of the paper including the volume, issue and page numbers.

Link to publication

\footnotetext{
General rights rights.

- You may freely distribute the URL identifying the publication in the public portal. please follow below link for the End User Agreement:

www.umlib.nl/taverne-license

Take down policy

If you believe that this document breaches copyright please contact us at:

repository@maastrichtuniversity.nl

providing details and we will investigate your claim.
}

Copyright and moral rights for the publications made accessible in the public portal are retained by the authors and/or other copyright owners and it is a condition of accessing publications that users recognise and abide by the legal requirements associated with these

- Users may download and print one copy of any publication from the public portal for the purpose of private study or research.

- You may not further distribute the material or use it for any profit-making activity or commercial gain

If the publication is distributed under the terms of Article $25 \mathrm{fa}$ of the Dutch Copyright Act, indicated by the "Taverne" license above, 


\title{
Oxygen and Cancer: Friends or Enemies?
}

\author{
Inaugural address
}

Summary spoken upon the acceptance of the position of Professor of Radiation-Oncology at Maastricht University on Friday, $14^{\text {th }}$ of September 2001 .

By

Prof. Dr. Philippe Lambin 
One's most important task in life is to become a useful person

$$
\text { (Japanese philosopher Sanjo). }
$$

Similarly, the mission of the new science is to become a useful and credible component of the modern medical armamentarium (American gene therapist David Curiel)

Tout ce qui est simple est faux, tout ce qui ne l'est pas est inutilisable.

(Pascal) 
A summary of this text was presented orally at Maastricht University on Friday, $14^{\text {th }}$ of September 2001.

Cancer is the second cause of mortality in the western countries and the incidence of cancer is increasing. Cancer is, in essence, a genetic disease involving multiple mutations, most of which are non-hereditary. The battle against cancer is not limited to improvements in cancer treatment; it also includes strategies for cancer prevention.

Oxygen is the most abundant element of the earth. It represents $8 / 9$ of the water mass and half of the mass of the earth"s crust. The fixation of oxygen is called combustion and results in the production of energy. With only a few exceptions such as gold, most of the elements can burn in oxygen. In living organisms respiration produces an oxidation of organic substance in tissues, which produces energy. Oxygen is necessary for life of all large living organisms.

Here we will review the role of oxygen or its absence (hypoxia) in the history of the war against cancer. As we will see oxygen, or the lack thereof, plays a critical role in both the development and treatment of cancer.

\section{Part I: The process of carcinogenesis}

\section{Cancer and ageing}

Cancer incidence increases with approximately the fifth power of age, both in short-lived species such as rats and mice and in long-lived species such as humans. Thus, cancer is one of the degenerative diseases of old age, although exogenous lactors can substantially increase il (e.g. cigarette smoking in humans) or decrease it (e.g. calorie restriction in rodents) (1).

In rodents, a high calorie diet appears to be carcinogenic. A calorie-restricted diet, compared with an ad libitum diet, significantly increases the life span of rats and mice and dramatically decreases the cancer rate. Although a causative mechanism to account for the beneficial effects of calorie restriction has not been established (there are hypotheses about this - the most current involving the protein SIR2 which is linked to NADH and energy metabolism), several physiological indices change in rodents raised on this dietary regimen. Among the principal changes that occur is the activation of the pituitary adrenocorticotropic axis that leads to a decrease in the release of reproductive and mitogenic hormones. This change may be an adaplive response to the decreased availability of food resources. Indeed, it has been suggested that Darwinian fitness will be increased if reproductive function is delayed during periods of low food availability and that the saved resources be invested in maintenance of the body until food resources are available for successful reproduction $(2,3)$. 
If one accepts the concept of a trade-off between reproduction and maintenance as predicted by evolutionary biology it becomes evident why calorie restriction is so effective in reducing all cancers. Decreases in mitogenic hormones such as insulin, thyroid stimulating hormone, growth hormone, oestrogen, and prolactin decrease the likelihood of hormone-induced cancers, as has been shown in various animal studies. In addition, cells from longer-lived species appear to have a higher intrinsic ability to maintain their proper differentiated state and animals whose life span has been extendled by food restriction also have a postponed onset of cancer. These data suggest the possibility that genetic instability may represent a common causative mechanism for both ageing and cancer. Evidence indicating that oxidative stress can increase cancer frequency and that longer-lived species appear to have a lower oxidative stress state supports this suggestion.

This is one of the oxygen paradoxe-ageing and cancer have a common cause even through ageing results from cell death and cancer from cell immortality.

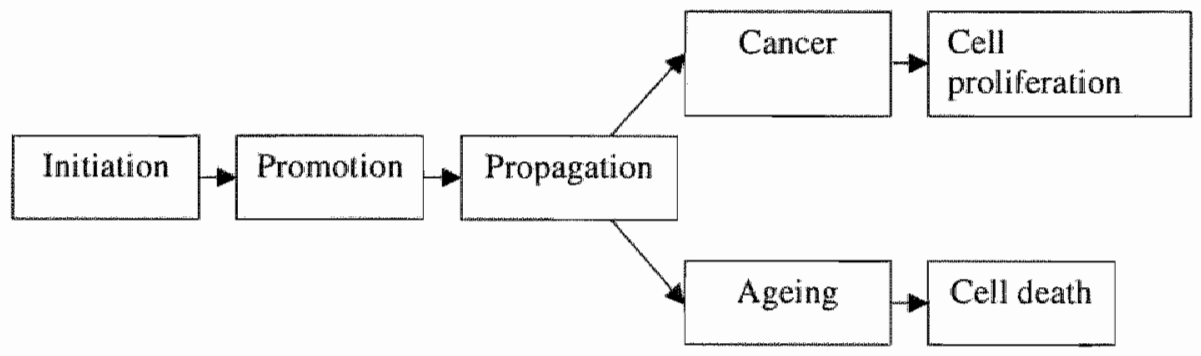

Figure 1: Multistep model of ageing and Cancer. This model represents the proposed multistep model of both cancer and ageing in their progress to increasing stages of dysdifferentiation. The ultimate end result of transformed cancer cells is cell proliferation and immortality, whereas for the ageing process (other than cancer) is cell death or loss of function. Figure from Cutler and Semsei, see (4).

\section{Cancer and oxidative damage}

The development of cancer is a multistage process, with the three main stages being defined as initiation, promotion and progression. Initiation is essentially damage to genetic material, such as a mutation that activates cellular proto-oncogenes or inactivates tumor-suppressor genes. Carcinogens are compounds that, usually after activation to a reactive intermediate, damage the DNA by direct interaction. Multiple cellular enzymatic systems exist to repair such damage to the DNA, but if is the damage is not repaired before cell division takes place then the mutation is often fixed and the cell has become initiated. This in itself is not sufficient to lead to the growth of a tumour. To progress through the final stage to a malignant tumour probably involves a further genetic change possibly as a result of inherent chromosomal instability. 
Four endogenous processes leading to significant DNA damage are likely to be oxidation, methylation, deamination, and depurination (2). The measurement of DNA adducts by new methods shows that DNA damage produced by oxidation could be the most significant endogenous damage.

Oxidants are produced as by-products of mitochondrial electron transport, various oxygen utilising enzyme systems, peroxisomes and other processes associated with normal aerobic metabolism, as well as by lipid peroxidation. Oxidants that escape the numerous antioxidant defences can damage callular macromalecules, including DNA, and such damage can lead to mutations and cancer. The total number of all types of oxidative hits to DNA per cell per day may be about $10^{4}$ in man and about $10^{5}$ in the rat.

In recent years, tremendous advances bave been made in our understanding of the mechanism of gene expression and of the role of reactive oxygen species in producing DNA damage. It has been established that oxygen free radicals* (such as superoxide, $\mathrm{O}_{2}{ }^{-}$and highly-reactive hydroxyl, $\mathrm{OH}^{*}$, radicals) $)^{* *}$ are constantly produced in living organisms. In addition, several non-radical oxygen-derived species (such as hydrogen peroxide and hypochlorous acid) are also generated. The term reactive oxygen species (ROS) is a collective one that describes both the oxygen radicals $\left(\mathrm{O}_{2}^{\circ}, \mathrm{OH}^{*}\right.$, also peroxyl $\left(\mathrm{RO}_{2}{ }^{*}\right)$ and alkoxyl ( $\left.\mathrm{RO} \mathrm{O}^{*}\right)$ radicals) and these other non-radical derivatives $\left(\mathrm{H}_{2} \mathrm{O}_{2}\right.$, $\mathrm{HOCl}$, singlet $\mathrm{O}_{2}$, ozone). Production of oxygenderived species in vivo is sometimes accidental, such as the generation of $\mathrm{OH}^{*}$ by the splitting of water due to our exposure to background ionising radiation or the generation of $\mathrm{O}_{2}{ }^{*-}$ by leakage of electrons from electron transport chains. Other sources of oxygen-derived species include those produced from normal metabolism in humans such as the reactive oxygen species required for phagocyte function and others that may be important as intercellular signalling molecules. Most reactive oxygen species generated in vivo are quenched by antioxidant defence systems. Humans do not have a large excess of antioxidant defences, perhaps because some reactive oxygen species have useful physiological roles. Hence oxidative damage to biological molecules is not completely prevented, and there is a need for repair systems, such as the enzyme systems that repair damaged DNA.

The high endogenous level of oxidative adducts reinforces data from epidemiological studies showing that a deficiency of antioxidants is likely to be an important risk factor for cancer. Epidemiologists have been accumulating evidence indicating that unbalanced diets are major contributors to heart disease and cancer and are likely to be as important as smoking.

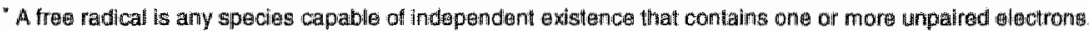

" $\mathrm{OH}$ is: often written "OH lo emphasize the location of the unparred electron ory oxygen atom.
} 
Cigarette smoke contains high concentrations of ROS, which are strongly implicated as causative factors in diseases related to smoking, particularly cancer. ROS from cigarette smoke also severely deplete the intracellular antioxidants in living cells by a mechanism related to increased oxidative stress. Furthermore, chronic cigarette smoking increases the number of neutrophils in lung fluid and particulate in the smoke (or other particles including fibbers) may activate these cells to produce increased amounts of ROS.

The relationship between cancer and oxidative damage is of practical interest, because it raises the possibility that the carcinogenesis process could be influenced by interventions that modify free radical reactions. Since we are principally dealing with oxygen-derived free radicals, natural or synthetic antioxidants may have the power of preventing cancer. Nevertheless further studies are required because most of the antioxidants products used so far also have an oxidative effect. Another potential pitfall is that the spontaneous consumption of dietary antioxidants and therefore the antioxidative state of different individuals can vary largely from one to another. A personalised approach is likely to be required.

\section{Presence and detection of Hypoxia in solid human tumours}

During the past 10 years it has become evident that solid human tumours very often contain regions that are deficient in oxygen (= hypoxic) (5). The presence of hypoxia has been demonstrated in cervical cancer, squamous cell carcinoma of the head and neck, melanoma, breast, sarcoma and more recently in prostate cancer. The oxygen levels are typically very heterogeneous both among patients and within individual tumours. Oxygenation status has primarily been measured using either polarographic oxygen electrodes or biochemical techniques that rely upon the antibody detection of nitroimidazole based adducts within hypoxic tissue (pimonidazole, EF5, EF1). Electrode $\mathrm{pO}_{2}$ data have been used extensively in clinical studies and are often referred to as the "gold standard" for determining tumour oxygenation status. However, these electrodes show no discrimination of cell type or viability and thus will record readings from less significant (radiobiologically speaking) tissue. Since pimonidazole and EF5 are selectively reduced only in viable hypoxic cells, they have a theoretical advantage for determination of relevant hypoxia. This may also explain why Eppendorf $\mathrm{pO}_{2}$ values do not al ways correlate with the nitroimidazole based hypoxia marker studies. Reliable methods of identifying patients with hypoxic tumours, preferably with non-invasive assays, will be increasingly important in the coming years as therapies targeting this aspect of the microenvironment approach use in the clinic.

\section{Hypoxia is associated with a poor prognosis: increased malignancy}

Recently, clinical and experimental data have suggested that conditions within the tumour microenvironment, most notably hypoxia, can influence patient prognosis 
by means other than treatment resistance bur as a contributor to the malignant phenotype. Hypoxia has been implicated in promoting metastasis, angiogenesis and selection of cells with a more malignant phenotype.

\section{a. Hypoxia promotes metastasis}

Several experimental models have shown that tumour hypoxia is associated with an increased ability to form metastases. Young and co-workers demonstrated many years ago that murine tumour cells exposed to severe hypoxia increased their metastatic potential (6). Other in vitro experiments utilising the vasculosa area of early chick embryos to grow human glioblastoma cells demonstrated that micovessel density was significantly increased under hypoxia, and that migration of tumour cells outside of the main tumour mass occurred only under hypoxic conditions. Hypoxia is able to promote turnour metastasis in two ways: 1) by inducing the expression of gene products involved in the metastatic cascade and 2) by providing selection pressure for a more aggressive phenotype (see next section). The initiation of metastasis is a multi-step pathway that involves three major processes: degradation of the basement membrane and extracellular matrix (ECM), modulation of cell adhesion molecules, and cell migration. Hypoxia plays a role in influencing several of these areas, thereby making it an attractive target to control tumour progression.

For example one study revealed that cell surface integrins and other adhesion molecules, such as CD44 and N-CAM, were transiently down-regulated upon exposure to hypoxia, leading to an associated decrease in adhesion to ECM components that returned to normal levels after reoxygenation (7). If similar changes should occur in vivo, this could have a significant effect on the migration of malignant cells from a hypoxic environment to a new site of tumour growth.

\section{b. Hypoxia selects cells with a more malignant phenotype.}

Hypoxia-mediated selection of tumour cells with a diminished apoptotic potential under hypoxic conditions has been suggested as an important biological mechanism for tumour progression. Graeber et al. used embryonic fibroblasts derived from wt and p53-deficient transgenic mice to investigate the role of p53 in hypoxiainduced apoptosis and showed that oncogenic transformation predisposed cells to hypoxia-induced killing through an apoptotic pathway modulated by p53 (8). They also demonstrated that apoptotic regions were more prevalent in $p 53^{+/+}$tumours than in $553^{\%}$ tumours and that apoptotic areas co-localized with hypoxic regions, distal to adjacent blood vessells. Based on the observation that in a mixture of transformed $\mathrm{p} 53^{-/ t}$ and $\mathrm{p} 53^{+/ t+}$ cells in a 1 to 1000 ratio, $553^{/ /}$cells had overtaken $\mathrm{p} 53^{+/+}$cells after multiple rounds of hypoxia and aerobic recovery, they concluded that hypoxia could also select for apoptosis-resistant cells. Drawn primarily from these experimental results, a mathematical model has been recently developed, that describes the effects of alternating periods of hypoxia and normoxia on tumours that contain wild-type and mutant p53 cells. Based on independent experimental results, the model can predict 
the lime it takes for a subpopulation of mutant p53 tumour cells to become the dominant population within defined tumour regions, both in witro and in wivo, and provides a qualitative insight into the belhaviour of mixed populations of wild-type and mutant cells growing under normoxic and hypoxic conditions. The selective pressure resulting from hypoxia is not limited to the selection of cells with reduced apoptotic potential. It has also been shown to provide a possible selection force for cells that have altered oncogenic pathways that result in a switch to a more angiogenic phenotype.

By promoting the cllonal expansion of cells with reduced apoptosis and increased angiogenesis, hypoxia can contribute to the development and malignancy of tumours. Recent clinical results showing that hypoxic cervical cancers with low apoptotic index are highly aggressive, strongly support this basic experimental concept.

\section{c. Hypoxia promotes angiogenesis}

Tumour progression requires the formation of new blood vessels - the process of angiogenesis - in order to provide nutrients and remove catabolites from the expanding tumour mass. Angiogenesis is also essential for the efficient dissemination of primary tumour cells during metastasis. The early steps of angiogenesis and tumour metastasis are nearly identical, as both processes involve degradation of the ECM and directed migration of either vascular or neoplastic cells. In addition, angiogenesis requires proliferation of the migrating endothelial cells. Initiation of angiogenesis begins when cells within the tumour microenvironment respond to hypoxia by the production of vascular endothelial growth factor (VEGF) (9). In vitro studies have shown that D12 melanoma cells expressing low VEGF levels under aerobic conditions, significantly increase VEGF secretion under hypoxia, and demonstrate increased angiogenesis and metastatic efficiency in mice. In addition to VEGF, hypoxia is also responsible for inducing expression of the VEGF receptors (VEGFR1 and VEGFR2) through HIF-1 mediated transcription. Thus, it would seem that hypoxia efficiently promotes an angiogenic signal by regulating both the VEGF ligand and its receptors.

\section{d. Clinical data}

Several clinical studies support the association between hypoxia and malignancy. Data in primary uterine cervix carcinoma, soft tissue sarcoma and squamous cell carcinoma of the head and neck showed that tumour hypoxia was prognostic for poorer outcome irrespective of treatment modality (e.g. 10). Different end points were evaluated, loco-regional control, disease free survival, disease specific survival or overall survival. In the study of Brizel et al, 63 patients with head and neck cancer receiwing primary radiotherapy underwent pre-treatment polarographic tumour oxygen measurement of the primary tumour or a metastatic 
neck lymph node. The median pO2 for primary lesions was $4.8 \mathrm{mmHg}$, and it was 4.3 $\mathrm{mmHg}$ for cervical nodes. Hypoxia adversely affected 2 year local control $(30 \mathrm{vs}$. $73 \%, \mathrm{p}=0.01$ ), disease-free survival ( 26 vs. $73 \%, \mathrm{p}=0.005$ ), and survival ( 35 vs. $83 \%, \mathrm{p}=0.02)$

In general, tumour hypoxia does not depend on clinical tumour size, clinical stage, histological type, grade, extent of necrosis, or patient hemoglobin levels, and is therefore an independent predictor of outcome. Based on these results, it has been proposed that tumour hypoxia may directly influence malignancy and that the poor prognosis of hypoxic tumours is not simply a result of resistance to therapy (10). Indeed, tumour hypoxia has been shown to promote lymph-vascular space involvement and parametrial infiltration in squamous cell carcinoma of the uterine cervix.

There is substantial evidence that hypoxia is associated with clinical metastases. The exact mechanisms are still to be revealed. Some suggestions for improving treatment strategies come from the study of Rof stad et al. in squamous cell carcinoma of the uterine cervix treated with radiotherapy. The authors argue that treatment failure was primarily a result of hypoxia-induced radiation resistance rather than hypoxia-induced lymph-node metastasis, suggesting that novel treatment: strategies aiming at improving tumour oxygenation or enhancing the radiation sensitivity of hypoxic tumour cells may prove beneficial to improve radiation therapy of advanced cervix carcinoma (11).

\section{Changes in gene expression that accompany hypoxia}

The multiple roles assigned to hypoxia, including the induction of angiogenesis, apoptosis, and metastasis, likely result in large part from changes in gene expression that accompany hypoxia. A significant number and wide variety of hypoxia-induced genes have been described. Changes in the expression of many of these genes serve to counteract hypoxia and increase oxygenation, while others affect the cellular adaptation to decreased oxygen levels or mediate death signal pathways.

Upregulation of growth factors and hormones such as wascular endothelial growth factor (VEGF), platelet-derived endothelial cell growth factor/thymidine phosphorylase (PDECGF/TP) and erythropoietin (EPO) results in endothelial cell proliferation and increased red blood cell production and serves lo restore oxygen availability. Expression of the VEGF receptor Flt-1 is also induced in endothelial cells under hypoxic conditions. As an adaptation to oxygen deprivation, cells need to shift their ATP production from oxidative phosphorylation to anaerobic glycolysis. Thus, the activity of glycolytic enzymes such as phosphoglycerate kinase-1 (PGK-1) and pyruvate kinase $\mathrm{M}$ (PK-M) is increased during hypoxia, and the expression of glucose importer proteins (GLUTs) are also induced. 
The regulation of gene expression under hypoxia has been shown to occur through many different mechanisms, including transcription, mRNA stability, translation and post-translational modifications. VEGF expression in particular is controlled at severall levels by hypoxia, including increased transcription initiated by the transcription factor HIF-1, enhancement of message stability by association with an RNA-binding protein HuR, and by increased production of a required chaperone protein ORP150. Cells exposed to hypoxia upregulate the expression of several transcription factors, including hypoxia-inducible factor (HIF-1), p53, AP-1, $\mathrm{C} / \mathrm{EBP} \beta$, early growth response 1 (Egr-1) and nuclear factor $\mathrm{KB}(\mathrm{NF} / \mathrm{B})$. Perlhaps the most important within this group is HIF-1, which induces the expression of more than 30 known genes (for a review see (12)), including EPO, VEGF, NOS2, Flt-1, GLUT1 and $-3, \mathrm{PK}-\mathrm{M}$ and IGF-2. The transcription of the $\mathrm{HIF}-1$ responsive genes is stimulated through the binding of HIF- 1 and other transcriptional activators to a hypoxia responsive element (HRE) in the gene promoter. HIF-1 is a heterodimer consisting of the two subunits, HIF- $1 \alpha$ and $\mathrm{HIF}_{-1} 1 \beta$. HIF-1 1 protein is stable, while HIF $1 \alpha$ is targeted for ubiquitination by the von Hippel-Lindau tumour suppressor protein (VHL) and rapidly degrated by the proteasome under well-oxygenated conditions. Thus, HIF- $1 \alpha$ is stabilized during bypoxia and can dimerize with its partner $\mathrm{HIF}_{-} 13$ to induce transcription of HRE-responsiwe genes (figure 3 ).

The oxygen paradox here is that oxygen contributes significantly to the production of initial mutations through oxidative damage but the lack of oxygen (hypoxia) has been shown to promote metastasis, angiogenesis and the selection of cells with a more malignant phenotype.

\section{Part II: The treatment of cancer}

Hypoxic tumours have a worse prognosis, another mechanism for this finding apart from its role in increased malignancy can be attributed to increased treatment resistance.

\section{Treatment resistance to Radiation}

For many years the importance of hypoxia in solid tumours was linked solely to the fact that hypoxic cells are intrinsically more resistant to Radiotherapy (see * note). The biological effects of radiation result principally from damage to DNA, which is the critical target. When any form of radiation-X-or by $\gamma$-rays, charged or uncharged particles- is absorbed in biological material, there is a possibility that it will interact directly with critical targets within the cell. The atoms of the target itself (normally DNA) may be jonized or excited, thus initiating the chain of events that leads to a biological change. This is the so-called 'direct' action of radiation. Alternatively, radiation may interact with other atoms or molecules in the cell (particularly oxygen of water) to produce free radicals that are able to diffuse far enough to reach and damage the critical targets. This is called the "indirect" action of 
radiation. For simplicity, we will consider what happens when radiation interacts with a water molecule, since $80 \%$ of a cell is composed of water. As a result of the interaction of a photon of $\mathrm{X}$ - or $\psi$-rays or a charged particle, such as an electron or proton, the water molecule may become ionized. This may be expressed as $\mathrm{H}_{2} \mathrm{O} \rightarrow$ $\mathrm{H}_{2} \mathrm{O}^{+}+\mathrm{e}^{-} \cdot \mathrm{H}_{2} \mathrm{O}^{+}$is charged and has an unpaired electron; consequently, it is both an ion and a free radical. Ion radicals have an extremely short lifetime, in the order of $10-{ }^{10}$ second. They decay to form free radicals, which are not charged but which still have an unpaired electron. In the case of water, the ion radical most often reacts with another water molecule to form the highly reactive hydroxyl radical $(\mathrm{OH})$ :

$$
\mathrm{H}_{2} \mathrm{O}^{+}+\mathrm{H}_{2} \mathrm{O} \rightarrow \mathrm{H}_{3} \mathrm{O}^{+}+\mathrm{OH}^{+}
$$

The hydroxyl radical possesses nine electrons, so one of them is unpaired. It is a highly reactive free radical and can diffuse a short distance to reach a critical target in a cell. For example, it is though that the hydroxyl radical can diffuse to DNA from within a cylinder with a diameter about twice that of the DNA double helix. It has been estimated that about two thirds of the X-rays damage to DNA in mammalian cells is due to the hydroxyl radical. The best evidence for this estimate comes from experiments using free radical scavengers, which can reduce the biological effect of sparsely ionizing radiations, such as X-rays, by a factor of close to 3 .

For the indirect action of X-rays, the chain of events, from the absorption of the incident photon to the final observed biological change, may be described as follows:

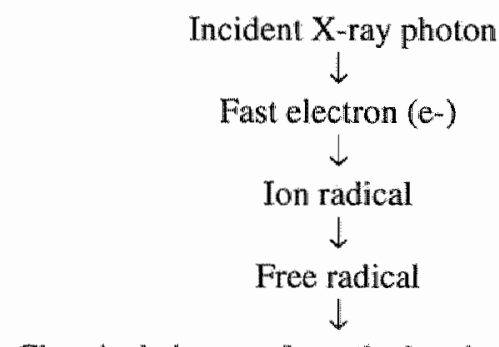

Chemical changes from the breakage of bonds

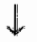

Biological effects (lower in hypoxia)

Figure 2: The indirect action of $\mathrm{X}$-rays

This is another oxygen paradox: cancer is mainly initiated by mutations due to oxidative damage but radiotherapy is able to cure cancer by producing DNA damage in cancer cells mainly through oxidative free-radical damage. 
Cells are much more sensitive to radiation in the presence of molecular oxygen than in its absence (i.e. under hypoxia). For ionizing radiation, the dose required to produce the same level of cell killing is up to 3 times higher for hypoxic cells as compared to well-oxygenated cells. Oxygen is most important immediately after damage to the DNA by these species - to fix the damage and prevent chemical repair of the transient DNA radical.

Importantly, tumour hypoxia has clinically demonstrated to predict an adverse treatrinent outcome in the radiotherapeutic management of cancer of the head and neck, uterine cervix, and soft tissue sarcomas. In head and neck cancer in particular, there is strong evidence that hypoxia is associated with poor outcome of radiotherapy in terms of loco-regional control, disease free survival and for overall survival. This poor prognosis due to hypoxia is independent of known prognostic parameters such as clinical stage.

- Note: What is radiotherapy? The treatment of cancer with ionising radiation is called Radiotherapy or Radiation Oncology. Radiotherapy is one of three main. disciplines within the science of oncology. The other two disciplines are surgery and chemotherapy. Radiotherapy is a clinical science, with clinical., physical (radiophysics) and biological (radiobiology) aspects. Radiotherapy can be given as external radiotherapy from outisde the body with $X$ rays or as internal radiotherapy (brachytherapy) when radioactive material is placed transiently within the body of the patient. During radiotherapy, the cancer cells are destroyed in the area that has been treated. Some of the healthy cells are within the treatment field and are also affected, but they receive a lower radiation dose. The damage to normal tissue is also less severe when compared to the tumour when radiation is given in many small fractions. In Europe, about $14 \%$ of all patients with cancer are cured with radiotherapy as the sole treatment and $10 \%$ in combination with the other two disciplines. Radiotherapy also plays also an important role in the palliation of cancer patients (relief of the symptoms caused by cancer). About 50 $\%$ of all the people with cancer are treated with radiotherapy as part of their treatment. In the past several years the delivery of radiation has improved dramatically with the development of new technology such as conformal radiotherapy, intensity modulated radiotherapy, stereotactic radiotherapy and many others... The next wave of improvement, already in progress, is based on biological initiatives: "new treatment strategies" such as hyperfractionation, accelerated radiotherapy, hypoxic cell sensitizers, biological modifiers and many others... This concept of "individualized radiotherapy "relies upon predictive assays of treatment outcome (for example, functional imaging, cDNA and proteins arrays). 


\section{Treatment resistance to Chemotherapy}

Chemotherapeutic drug resistance in hypoxic cells is also partially caused by reduced toxicity in the absence of molecular oxygen. Some agents, such as bleomycin, require free radicals in their mechanism of cell killing. Chemotherapeutic drug resistance can also be caused by the hypoxia-induced inhibition of cell proliferation, since a number of drugs specifically target highly proliferating cells. Prolliferation decreases as a result of decreasing oxygen levels, and it has been shown that the drug toxicity falls off as a function of distance from blood vessels. Furthermore, chemotherapeutic drug delivery to hypoxic areas is challenged since tumour hypoxia itself arises from insufficient and distorted vasculature. Thus the effective dose to hypoxic regions may be much less than to other parts of the tumour (13).

\section{How can we fight tumour hypoxia?}

The realisation that hypoxia is a common characteristic of human tumours that adversely effects patient prognosis suggests that targeting hypoxia will be an effective means of improving treatment. Scientists and clinicians alike are using two fundamentally different approaches to tackle the problems of hypoxia. The first approach is to improve or restore normal tumour oxygenation, and the second approach is to exploit the unique property of tumour hypoxia for targeting treatment to the tumour. The success of these two approaches will ultimately depend upon the relative importance of hypoxia in treatment resistance and malignancy.

\section{A. Improve oxygenation of tumours}

Attempts to increase the oxygen supply to the hypoxic yet potentially viable tumour cells has been a major goal of experimental and clinical research for over 40 years. Various strategies have been considered including hyperbaric or increased oxygen breathing, the administration of hypoxic cell sensitizers, and more recently erythropoietin to improve the haemoglobin level and to avoid repeated transfusions. Although most of the early attempts to overcome hypoxia have led to mixed results, in head and neck cancer a large meta-analysis of these trials has shown that oxygen modification results in a significant improvement in local control and diseasespecific survival.

\section{A.1. Erythropoietin}

Erythropoietin (EPO) is a glycoprotein hormone produced by the kidney in response to tissue hypoxia that stimulates red blood cell production in the bone marrow. Currently there is active interest in using recombinant human EPO in patients with low haemoglobin (Hb) levels in order to improve umour oxygenation. 
The hypothesis is that some hypoxic tumours may result from low Hb levels in anaenic patients or even in patients with a $\mathrm{Hb}$ in the lower part of the normall range. Hb concentration has been shown to be an important prognostic factor for the oukcome of various cancer types treated by radiotherapy. Most of the clinical studies published have shown better tumour control in patients with higher Hb level than in patients with $\mathrm{Hb}$ in the lower part of -or below- the normal range (e.g. 14). There seems to be a good documentation for the effect of $\mathrm{Hb}$ on radiation response in carcinoma of the uterine cervix, in head and neck cancer, in bronchogenic carcinoma, in bladder carcinoma and prostate carcinoma. Overall, patients with low haemoglobin levels have lower local control and surwival. The only prospective study on the effect of transfusion on tumour control is a small study in carcinoma of the cervix. Patients who were transfused to maintain their Hb level above $13.5 \mathrm{~g} / \mathrm{dl}$ showed significant improved local control rates.

In oncology, EPO is known to increase the $\mathrm{Hb}$ level in cancer patients without interfering with their course of radiation therapy. For example a study with 60 andemic head and neck patients patients treated with neo-adjuvant radiochemotherapy and EPO experienced more complete pathological responses as compared to that of a historical control group (67 versus 27\%) (15). At the moment several phiase 3 trials are running (one of them in Maastricht) to test the hypothesis that increase of $\mathrm{Hb}$ with EPO during radio or chemotherapy has the ability to improve outcome.

\section{A.2. Accelerated radiotherapy combined with carbogen and nicotinamide (ARCON)}

The ARCON protocol is currently being evaluated in the clinic. Carbogen $\left(95 \% \mathrm{O}_{2}+5 \% \mathrm{CO}_{2}\right)$ is used to reduce diffusion limited or chronic hypoxia, and nicotinamide is added to reduce acute hypoxia resulting from temporary vasculature shut-down. The use of these agents simultaneously has indeed been shown to increase the radiation damaging effect in a variety of rodent tumour models.

Increased oxygenation of tumours treated with carbogen and nicotinamide has been demonstrated in patients. Promising results have been obtained in several nonrandomised clinical studies using this combination in conjunction with accelerated irradiation. The Nijmegen radiotherapy group reported a significant beneficial effect for the treatment of advanced laryngeal tumours as compared with historical conventional radiation therapy data, both in terms of loco-regional control and survival (16). Phase II clinical results obtained for bladder carcinoma also showed a significant increased local control and overall survival from the triple combination treatment, when compared with previous experiences using standard radiotherapy.

A randomised phase III clinical trial, co-ordinated by the colleagues and friends of the university hospital of Nijmegen, has been recently started to ultimately determine the success of this protocol. 


\section{A.3. Hypoxic radiosensitisers}

Many years have been dedicated to the search and development of compounds that could substitute for oxygen at the time of radiotherapy. This approach was based on the concept that these compounds could mimic the effects of oxygen at the time of radiation delivery, thereby increasing. DNA damage and restoring radiosensivity. However, most of the compounds developed could not be administered to patients at effective concentrations with acceptable toxicity. Nonetheless, hypoxic sensitizers continue to be developed and used in some instances. Nimorazole, a 5-nitroimidazole derivative, has been widely used as an antimicrobial agent. Significant or chronic toxicity has been absent from the phase I and II studies involving the use of nimorazole. In a large double-blind randomised phase III trial in Denmark, nimorazole was reported to significantly improve the effect of radiotherapy of supraglottic and pharynx tumours while the toxicity of the drug was mild (17). This result was highly significant, and nimorazole has now been incorporated into the standard treatment of most head and neck cancer patients in Denmark.

\section{B) Exploit the microenvironment}

The second approach to combating hypoxia is fundamentally different from attempts to restore or replace oxygen. In this scenario, the unique property of tumour hypoxia is used as an advantage for targeting cancer treatment. There are 3 primary means by which this targeting is currently being attempted. The first is to target the lack of oxygen per se, for example by using bioreductive drugs that are only toxic in the absence of oxygen. The second is to exploit the unique features of the tumour vasculature that are both responsible for and a consequence of tumour hypoxia. Finally, one can target the known molecular and cellular biological responses to hypoxia.

\section{B.I. Target hypoxia per se}

\section{B.I.I. Bioreductive drugs}

Bioreductive drugs are compounds that are reduced by biological enzymes to their toxic, active metabolites. They are designed such that this metabolism occurs only or preferentially in the absence of oxygen. The use of these drugs in combination with traditional therapies has the potential to greatly improve treatment outcome by increasing cytotoxicity to the hypoxic fraction. Tirapazamine (TPZ) is the leading compound in this class of agents and has shown promising results in a number of clinical trials when used in combination with cisplatin and/or radiotherapy. A wide number of cell lines are sensitive to TPZ, regardless of their p53 status, and require 50-150 times higher dose for the same toxicity under aerobic conditions (18). The mechanism of this preferential toxicity is mediated by an enzymatically catalysed one-electron reduction of TPZ, which yields a highly reactive radical 
capable of causing cell death by producing various types of DNA damage. In the presence of oxygen, the TPZ radical is rapidly back oxidised to the non-toxic parental compound, thus minimising toxicity to well oxygenated tissues.

\section{B.1.2. Gene therapy with bacterial vectors}

The aim of gene therapy is to transfer genetic material to the tumour cell or its microenvironment in quantities sufficient to obtain a therapeutic level of expression. However, strategies devised to date have limited efficiency, most notably due to deficiencies in the delivery systems employed. A recent approach to this problem employs the concept of targeting anaerobic bacteria to the hypoxic/necrotic areas of solid tumours. An association between bacteria and tumours dates back more than 100 years ago when William Coley found that certain patients who contracted bacterial infections recovered remarkably well from certain cancers. Currently, Clostridium spp. and attenuated Salmonella typhimurium auxotrophs are being investigated at several research centres as systems to deliver anti-tumour compounds specifically to the tumour site $(19,20)$. The latter strain grows under aerobic and anaerobic conditions, with selectivity for tumours reported as a consequence of its auxotrophic nature. The specificity of clostridia for tumours resides in its obligate requirement for anaerobic conditions. Intravenously injected spores of a nonpathogenic clostridial species have been shown to localise to, and germinate in, the hypoxic/necrotic regions of solid tumours. Although growth alone in the tumour is not sufficient for therapeutic efficacy, the possibility now exists to engineer Clostridium spp. to produce a variety of therapeutic proteins with anti-cancer properties. Clostridia can thus be used as highly selective in-situ cell factories able to produce and secrete anti-tumour therapeutics specifically at the tumour site. Moreover, it has been shown that the immune response does not hinder repeated administration of clostridial spores, that colonisation can be improved using vascular targeting treatment (see next section) and that gene expression can be stopped at any time using suitable antibiotics. We and others demonstrated that it is possible to express therapeutic proteins, not only in witro, but also in wivo after administration of the recombinant clostridia to tumour-bearing animals $(21,22)$. These experiments demonstrate that the principle of using the Clostridium vector system, or other non pathogenic bacteria is feasible and holds considerable promise for tumour specific therapy.

\section{B.1.3. Use of radio-inducible promoters in Clostridium}

To further increase the specificity of this tumour-directed delivery system, the gene of interest may be placed under the control of a radio-induced promoter. This will result in an activation of the promoter after irradiation of the tumour, leading to spatial and temporal control of gene expression (i.e. expression of the therapeutic genes will be limited to the irradiated tissues only). Radio-inducible promoters are being used in many viral vector systems to achieve spatial and temporal control of gene expression. Our group investigated if radiation-induced gene expression could 
also be attained in a bacterial vector system using anaerobic non-pathogenic clostridia. We found a radio-induction of the recA gene, a central gene involved in the $\$ O S$ repair system of bacteria, which was evident already at the clinically relevant dose of $2 \mathrm{~Gy}$. When we quantified the degree of induction of the recA promoter using a reporter system, an overall $30 \%$ significant increase in activity was detected (23). More important we found that the radio-induction is repeatable following a second radiation dose which is particularly important for the clinic because the patients are usually treated by daily radiation dose.

Thereafter, we examined if we could suppress basal transcription by adding an extra repressor-binding site, or Cheo box, to the promoter region. After activation by radioherapy, both binding sites would become free and repression would be relieved. This would lead to an increase in transcription of the SOS genes, including recA, after radiotherapy. Indeed, addition of an extra Cheo box to the recA promoter resuited in a $412 \%$ increase of secreted InTNF- $\alpha$ after irradiation, while only $44 \%$ yield increase was obtained using the wild-type promoter. Hence, the Cheo box sequence is the radio-responsive element and can be used to decrease basal transcription or to increase transcription upon induction. Taken together, these data show the proof-of-principle that radio-induced promoters can be used to control expression of therapeutic proteins by recombinant clostridia. The combination of radiotherapy, which preferentially kills well-oxygenated cells, with Clostridiummediated protein delivery to target the hypoxic fraction, opens new possibilities for the future of cancer therapy.

\section{B.2. Exploit tumour vascullature}

Abundant evidence has demonstrated that solid tumours require an expansion of the blood supply to provide their oxygen and nutritional requirements. Yet in tumours, this process of angiogenesis results in disproportional and inadequate vascular architecture, with vessels that are structurally and functionally different from those in normal tissues. Consequently, this abmormal intra-tumoural vessel network, which elicits a high rate of endothelial cell proliferation, offers an ideal target for novel therapeutic strategies, such as anti-angiogenesis and vascular targeting.

\section{B.2.1. Antiangiogenesis}

Angiogenesis is a complex biological process that offers potential therapeutic targets at many points (24). The target population most often consists of actively dividing and migrating vascular endothelium from established normal host and tumour vessels. Many of the current strategies for therapeutic anti-angiogenesis involve the blockade of angiogenic growth factors and the suppression of endothelial cell recruitment through small molecule receptor blockers, specific antibodies or the use of endogenous inhibitors. The five classes of angiogenesis antagonists in current clinical trials include molecules that block matrix breakdown, inhibit endothelial cells 
directly, block activators of angiogenes is, inhibit endothelial-specific integrin/stirvival signalling and distinct mechanisms of action.

\section{B.2.2. Vascular targeting}

The concept of "vascular targeting" was championed many years ago and has recently become a very active area of research. This concept refers to the use of agents that exploit vasculature features that are unique within the tumour. Several advantages of targeting the vasculature have been presented including: (i) potential efficacy against any solid tumour since the main target is the endothelial cell lining, (ii) lack of treatment-induced resistance, since endothelial cells are genetically stable, (iii) accessibility of the drug and target, and (iv) indirect killing of many thousands of twmour cells from vessel damage and subsequent nutrient deprivation. This approach would also result in killing of those cells that are at intermediate levels of hypoxia, resistant to classical therapies.

Combretastatin A-4 phosphate (CA-4P), a tubulin-binding compounds, is the leading compound in this class of agents and has been selected from this family for pre-clinical and clinical evaluation. A single CA-4P dose of $1 / 3^{\text {td }}$ to $1 / 10^{\text {th }}$ of the maximum tolerable dose (rat or mouse experiments respectively) results in rapid blood vessel damage, and subsequently tumour necrosis. Typically CA-4P results in central tumour necrosis, leaving a viable rim of cells on the edge of the tumour. CA$4 \mathrm{P}$ also appears to be much more effective in large tumours $\left(>7 \mathrm{~cm}^{3}\right)$ as compared with small $\left(<1 \mathrm{~cm}^{3}\right)$ tumours. The mechanism of action of CA-4P seems to result from a cell shape change that occurs in newly formed endothelial cells, resulting in blood vessell occlusion and total vascular shut-down. Currently a limited number of phase I clinical studies in the United States and the United Kingdom examine the impact of CA-4P on tumour physiology as well as general compliance and normal organ function.

This is another axygen paradox: hypoxia increases malignancy of tumours and increases treament resistance, but induction of severe, acute hypoxia (in fact anoxia) has also a the rapeutic effect.

\section{B.3. Exploit the biological responses to hypoxia}

The final strategy being pursued to target hypoxia is based on exploiting the recently understood biological responses to hypoxia. As described earlier, cells respond to hypoxia by modulating the expression of many genes. These changes in gene expression, in turn, cause a cellular and tissue response to hypoxia that affects both the cellular sensitivity to treatment and the processes of metastasis and angiogenesis. By targeting the early steps in the activation of these pathways, one may develop more specific and effective types of therapy. 
Various biological responses to hypoxia can be viewed in a generalised sequence of four successive steps. The first step is carried out by an oxygen sensor a protein that is capable of sensing and responding to reduced levels of oxygen. Activation of the sensor causes a molecular response consisting of the activation of downstream signalling pathways. This molecular response, in turn, leads to a cellular response, and finally a tissue or tumour response. In the past several years, we have learned much about one of the main hypoxic biological response pathways in mammalian cells - that involving the HIF-1 transcription factor. This pathway serves as a good example of this general response sequence and for how this knowledge can be translated into new cancer therapies.

Two recent reports suggest that the oxygen sensor in the HTF-1 pathway is a prolyl hydroxlyase. This enzyme, designated HIF-PH, requires oxygen for its activity (hydroxylation of proline residues). In this example, the molecular response to hypoxia is initiated as a result of reduced hydroxylation of a proline residue in the HIF-1 $\alpha$ subunit. Reduced hydroxylation prevents the recognition of HIF-1 $\alpha$ by the VHL ubiquitin ligase, thereby preventing ubiquitination. As a result, $\mathrm{HIF}_{-1} 1$ is stabilized and can transactivate its many targets, such as EPO, VEGF, and GLUT-1. These changes in gene expression lead to a cellular response that may consist of increased glycolysis in the tumour cells or activation of endothelial cell proliferation and migration by binding of VEGF to its receptor (26).

The important part of this illustration is that a detailed biological understanding of this pathway offers a plethora of options for targeting cancer treatment to the tumour. For example, an attractive molecular treatment would be one based on augmenting the activity of the oxygen sensor itself. Since the multiple cellular and tissue effects stem from this one initial protein, it provides a very specific and potent treatment target. There are already many examples of research clirected against the second level of this pathway. Several compounds designed to alter the activity of HIF-1 the von Hippel-Landau tumour suppressor protein (VHL), or the ubiquitin system itself are being explored in cancer treatment (27). At the level of the cellular response, antibodies and inhibitors of both VEGF and its receptor Flk-1 have been developed (as discussed under antiangiogenesis strategies). Recent reports suggest that inhibiting the ability of tumour cells to shift to glycolysis would also be advantageous (28).

The HIF-1 pathway is relatively well understood and serves as a good example of how knowledge of the biological responses to hypoxia can translate into new therapies. However, there are numerous other molecular and cellular responses to hypoxia that are independent of HIF-1, perhaps each with unique oxygen sensors. Continued research into the basic molecular and cellular responses of hypoxia will undoubtedly contribute further to the development of novel hypoxia based cancer therapies. 


\section{1) Semat:}

activity of an oxygen

dependent prolyl hyorowylase

- target activity of hydroxylase

2) Molecwion responste:

reduced hydroxylation of HF rediced affinity for VHL gene transeription (VEGF, PGK etc)

- target activity of VHL

- ubiquitin pathway modification

- gene therapy - HRE

3) Cellular response:

secretion of VEGT

activation of $\mathrm{VEGFR}$

anaerobic metabolism

- antibodies/inhibitors for VEGF

- antibodies/inhibitors of VEGFR

- inhibitors of glycolysis

4) Tissitudtumowr response:

angiogenesis

proliferation/surwival

- downstream angiogenesis inhibitors

- proliferation/survival modifying agents
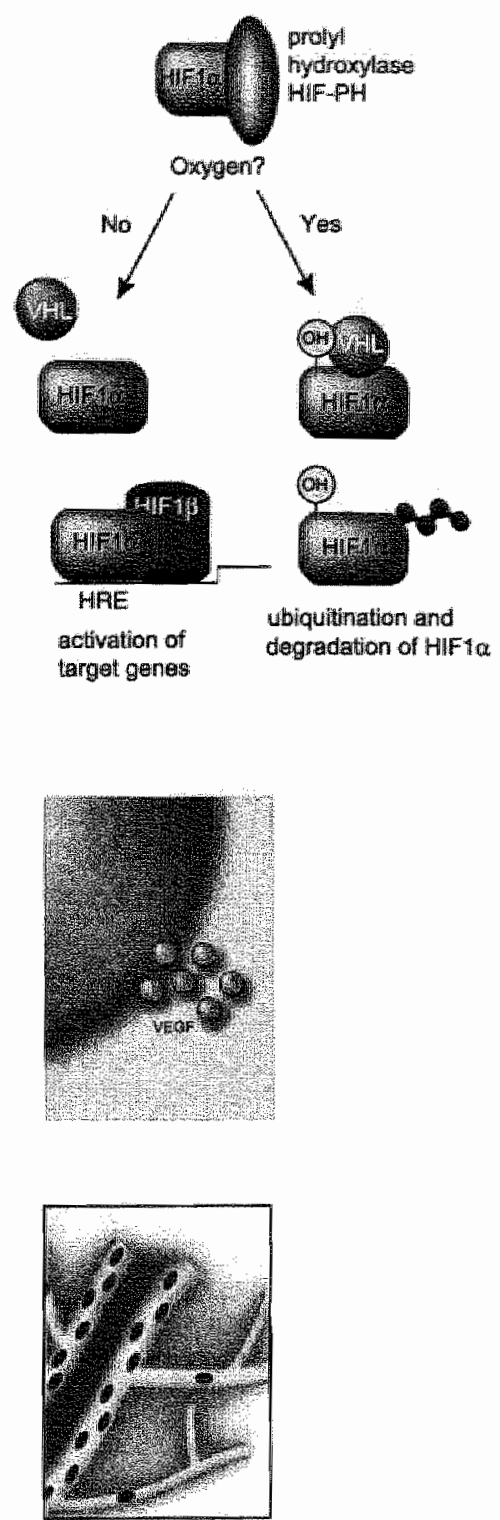
Figure 3: Biological responses to hypoxia can be viewed in terms of 4 successive steps. The HIF-1 pathway serves as an example of such a response. The first step is to sense that oxygen is limiting and in the HIF-1 pathway this is carried out by an oxygen dependent prolyl hydroxylase. The second step is the initiation of a molecular response through the activation of downstream signalling pathways. In this example, this results in the activation of several classes of genes as a result of stabilisation of the HIF- $1 \alpha$ subunit. A cellular response occurs due to these changes in gene expression, in this case resulting in a switch to anaerobic metabolism and secretion of angiogenic factors. Finally a tumour/tissue response occurs. In the HIF-1 pathway this may be the induction of angiogenesis in the tumour microenvironment together with increased survival and proliferation of the tumour cells. Each of these steps in the biological response to hypoxia is an opportunity for targeting therapy as indicated below each box..

\section{Conclusions}

"Oxygen and cancer: friends or enemies?" The answer to this "anthropomorphic" question is obviously "both". Oxygen contributes significantly to the production of the initial mutations through oxidative damage and also allows the cancerous cells to produce energy through respiration. The lack of oxygen (hypoxia) is a key feature of solid tumours and has been shown to promote metastasis, angiogenesis and to select cells with a more malignant phenotype. In the therapeutic area, oxygen is needed to effectively kill cancer cells with radiation. The most exciting features of this story are the opportunities, some already implemented into daily practice, of modulating the effects of oxygen. In the area of cancer prevention, modulation of the effect of oxygen can be achieved through agents such as antioxidants while in the therapeutic area it can be achieved by improving tumour oxygenation or through even more attractive methods by taking advantage of tumour hypoxia for targeting treatment.

Future prospects: "The best way to predict the future is to create it"

\section{At Maastricht:}

At the moment several approaches are currently being tested in our laboratory of radiation biology and in clinical trials at Maastricht. Our laboratory is actively exploring the molecular basis for the malignant phenotype exhibited by cells lacking oxygen. At the same time, we are developing strategies to exploit tumour hypoxia for improved therapy. Research through clinical trials, already started or about to be started, in Maastricht includes studies on dietary Selenium (Department of Epidemiology), a phase I trial with bacterial vectors for gene delivery (together with the Department of Medical Oncology), phase III trials of radiotherapy with carbogen and nicotinamide (in collaboration with our colleagues in Nijmegen) and phase III 
trials with radiotherapy and erythropoietin (in collaboration with our colleagues of the head and neck tumour group). The aims of these trials are obviously to validate the hypotheses outlined here following the rigorous concept of evidence-basedmedicine.

\section{The coming biological and demographic revolution}

The oxygen story serves as a good example announcing the coming biologicat revolution. One of the consequences of this change will be a transition from spending a lot of time and resources on standardising treatment in oncology to customising it to each patient on the basis of the biological features of their tumour and/or normal tissues. Continuing the example of oxygen and carcer, we will need to individualise both primary prevention through the antioxidant status of patients, as well as to adapt treatment to patients with hypoxic tumours by choosing appropriate strategies that reflect the type of hypoxia and genetic defects of individual tumours. "Individualisation of treatment" is an old concept but we now have the tools to implement it, such as more advanced imaging techniques and functional genomic and proteomic approaches. The university of Maastricht has understood this concept, for example by recently launching the "proteomic centre of Maastricht".

These biological and technical developments are occuring in concert with a profound demographic revolution. The increase of elderly people combined with fewer physicians and scientists will oblige us to rethink parts of the health care process. No longer will it be possible or wise for patients to go successively to different specialists. A more practical and efficient approach would be for patients to be treated by disease specific teams (the concept of an oncological centre). An even more forward-looking approach would be the creation of a structure integrated with physicists, molecular biologists, various scientists, nurses and technologists. Such a structure would be perfectly suited to face both the coming biological and demographic revolution. The university of Maastricht is also moving towards this direction.

I am looking forward to live and work during these exciting times! 


\section{Acknowledgements:}

I am now at the end of my address, where I would like to thank several people who made my nomination in Maastricht possible: first of all Loes Klaasse who was my first contact with Maastricht and then Jan Carpay and Professor Gauke Kootstra who made it possible to start an brand new academic Radiation-Oncology Department. I would like to thank several people who have inspired me professionally this last decade including Prof. Pierre Scalliet from the Catholic University of Louvain in Brussels, Dr Andrew Kramar and Dr Edmond Malaise from the Institute Gustave Roussy in Paris, Prof. Mike Joiner from the Gray Laboratory in London, Prof. Emmanuel van der Schueren, Prof. Walter van den Bogaert, Prof. Allan van Oosterom and Prof Jozef Anné from the Katholieke Universiteit van Leuven. Thank you also to my colleagues of Maastricht who helped me in the preparation of this talk More specially Prof. Aalt Bast and Guido Haenen, Dr Brad. Wouters and his colleagues and Rianne Herben and Simone Walraven for their secretarial support. 1 would like to acknowledge my new colleagues who have come from different parts of the world (Canada, Norway, Belgium, Switzerland, Germany and even Amsterdam) with their families, thank you for your trust. And last but not least, $\mathbb{I}$ would like to thank my family and my children for whom there are no words to express my love.

Ik heb gezegd. 


\section{Selected references}

1. Roe FIC, Lee PN, Conybeare $G_{4}$, Tobin $G$, Kelly D, Prentice D and Matter B. Risks of premature death and cancer predicted by body weight in early adult life. Human Experimental Toxicology; 1991, 10: 285-288.

2. Ames $\mathrm{BN}$, Shigenaga $\mathrm{MK}$. Oxidants are a major contributor to cancer and ageing. In: DANA and free radicals. Ed.Halliweil B and Aruoma OI. ISBN: 0-13-222035$0,1993,2-15$.

3. Harman D. Free radical theory of aging: History. In: Free radicals and aging. Ed. by Emerit I. and Chance B. ISBN: 3-7643-2744-9. 1992, 1-10.

4. Cutler $\mathbb{R C}$. Genetic stability and oxidative stress: Common mechanisms in aging and cancer. In. Free radicals and aging. Ed. by Emerit I. and Chance B. ISBN: 3 7643-2744-9. 1992, 31-46.

5. Vaupel P, Schlenger K, Knoop C, Hockel M. Oxygenation of human tumors: evaluation of tissue oxygen distribution in breast cancers by computerized $\mathrm{O} 2$ tension measurements. Cancer Res 1991;51(12):3316-22.

6. Young SD, Marshall RS Hill RP. Hypoxia induces DNA overreplication and enhances metastatic potential of murine tumor cells. Proc Nati Acad Sci U S A $1988 ; 85(24): 9533-7$.

7. Hasan NM, Adams GE, Joiner MC, Marshall JF, Hart IR. Hypoxia facilitates tumour cell detachment by reducing expression of surface adhesion molecules and adhesion to extracellular matrices without loss of cell viability. $\mathrm{Br} J \mathrm{Cancer}$ 1998;77(11):1799-805.

8. Graeber TG, Osmanian C, Jacks T, Housman DE, Koch CJ, Lowe SW, et al. Hypoxia-mediated selection of cells with diminished apoptotic potential in solid tumours. Nature 1996;379(6560):88-91.

9. Semenza GL. Regulation of hypoxia-induced angiogenesis: a chaperone escorts VEGF to the dance. J Clin Invest 2001;108(1):39-40.

10.Brizel DM, Scully SP, Harrelson JM, Layfield LJ, Bean JM, Prosnitz LR, et al. Tumor oxygenation predicts for the likelihood of distant metastases in human soft tissue sarcoma. Cancer Res 1996;56(5):941-3.

1. Rofstad EK, Sundfor $\mathrm{K}$, Lyng $\mathrm{H}$, Trope CG. Hypoxia-induced treatment failure in advanced squamous cell carcinoma of the uterine cervix is primarily due to 
hypoxia-induced radiation resistance rather than hypoxia-induced metastasis. Br J Cancer $2000 ; 83(3): 354-9$.

12.Semenza GL. Hypoxia-inducible factor 1: control of oxygen homeostasis in health and disease. Pediatr Res 2001;49(5):614-7.

13.Lee WR, Berkey B, Marcial V, Fu KK, Cooper JS, Vikram B, et al. Anemia is associated with decreased survival and increased locoregional failure in patients with locally advanced head and neck carcinoma: a secondary analysis of RTOG 85-27. Int J Radiat Oncol Biol Phys 1998;42(5):1069-75.

14.Lee WR, Berkey B, Marcial V, Fu KK, Cooper JS, Vikram B, et al. Anema is associated with decreased survival and increased locoregional failure in patients with locally advanced head and neck carcinoma: a secondary analysis of RTOG 85-27. Int J Radiat Oncol Biol Phys 1998;42(5):1069-75.

15.Glaser CM, Millesi W, Kornek GV, Lang S, Schull B, Watzinger F, et al. Impact of hemoglobim level and use of recombinant erythropoietin on efficacy of preoperative chemoradiation therapy for squamous cell carcinoma of the oral cavity and oropharynx. Int J Radiat Oncol Biol Phys 2001;50(3):705-15.

16. Kaanders JH, Pop LA, Marres HA, Liefers J, van den Hoogen FJ, van Daal WA, et al. Accelerated radiotherapy with carbogen and nicotinamide (ARCON) for laryngeal cancer. Radiother Oncol 1998;48(2):115-22.

17.Overgaard I, Hansen HS, Overgaard M, Bastholt L, Berthelsen A, Specht L, et al. A randomized double-blind phase III study of nimorazole as a hypoxic radiosensitizer of primary radiotherapy in supraglottic larynx and pharynx carcinoma. Results of the Danish Head and Neck Cancer Study (DAHANCA) Protocol 5-85. Radiother Oncol 1998;46(2):135-46.

18. Wouters BG, Wang LH, Brown JM. Tirapazamine: a new drug producing tumor specific enhancement of platinum-based chemotherapy in non-small-cell lung cancer. Ann Oncol 1999;10(Suppl 5):S29-33.

19. Lambin P, Theys J, Landuyt W, Rijken P, Van der Kogel A, van der Schueren E, et al. Colonisation of Clostridium in the body is restricted to hypoxic and necrotic areas of tumours. Anaerobe 1998;4:183-188.

20.Pawelek JM, Low KB, Bermudes D. Tumor-targetted Salmonella as a novel anticancer vector. Cancer Res 1997;57(20):4537-44.

21. Theys J, Landuyt W, Nuyts S, Van Mellaert L, van Oosterom A, Lambin P, et al. Specific targeting of cytosine deaminase to solid tumors by engineered Clostridium acetobutylicum. Cancer Gene Ther 2001;8(4):294-7. 
22. Lemmon MJ, van Zijl P, Fox ME, Mauchline ML, Giaccia AJ, Minton NP, et all. Anaerobic bacteria as a gene delivery system that is controlled by the tumor microenviroument. Gene Ther 1997,4(8):791-6.

23. Nuyts S, van Mellaert L. Theys J, Landuyt W, Bosmans E, Anne J, Lambin P. Radio-responsive recA promoter significantly increases TNFalpha production in recombinant clostridia after 2 Gy irradiation. Gene Ther. 2001 Aug;8(15):1197. 201 .

24. Folkman J. Tumor angiogenesis: therapeutic implications. N Engl J Med $1971 ; 285(21): 1182-6$.

25. Landuyt W, Verdoes O, Darius DO, Drijkoningen M, Nuyts $\mathrm{S}$, Theys $\mathrm{J}$, et al. Vascular targeting of solid tumours: a major 'inverse' volume-response relationship following combretastatin $\mathrm{A}-4$ phosphate treatment of rat rhabdomyosarcomas. Eur J Cancer 2000;36(14):1833-43.

26.Seagroves TN, Ryan HE, Lu $\mathrm{H}_{*}$ Wouters $\mathrm{BG}$, Knapp M, Thibault $\mathrm{P}$, et al. Transcription factor hif- 1 is a necessary mediator of the pasteur effect in mammallian cells. Mol Cell Biol 2001;21(10):3436-44.

27.Kung AL, Wang S, Klco JM, Kaelin WG, Livingston DM. Suppression of tumor growth through disruption of hypoxia-inducible transcription. Nat Med $2000 ; 6(12): 1335-40$.

28. Ryan HE, Poloni M, McNulty W, Elson D, Gassmann M, Arbeit JM, et al. Hypoxia-inducible factor-1alpha is a positive factor in solid tumor growth. Cancer Res 2000;60(15):4010-5.

29. Wouters BG, Weppler S, Koritzinsky M, Landuyt W, Nuyts S, They J, Chiu and Lambin P. Hypoxia as a target for combined modality treatments. Review paper accepted in the Eur J of Cancer.

\section{Note:}

- You can get more detailed informations on this topic in one of our recently published reviews on tumour hypoxia $((29)$, send your request to p.lambinsec(@ril.ni).

- You can get more informations about our research activities by visiting our websile www.radiotherapie.umimaas.nl. 